\title{
LOS RETOS DEL DERECHO FRENTE AL AVANCE DE LAS NUEVAS TECNOLOGÍAS EN REPRODUCCIÓN HUMANA ASISTIDA: UN CASO DE VIENTRE SUBROGADO
}

\author{
THE CHALLENGES OF LAW AGAINST THE ADVANCE OF NEW \\ TECHNOLOGIES IN ASSISTED HUMAN REPRODUCTION: \\ A CASE OF SURROGATE
}

\author{
Roxana Rodríguez-Cadilla Ponce*
}

\section{Resumen}

Las denominadas Técnicas de Reproducción Humana Asistida (TERAS) constituyen una verdadera revolución tecnológica que viene siendo aplicada a la vida y a la procreación humana. Los llamados "milagros" de la ciencia moderna han permitido dar solución a uno de los problemas de mayor preocupación para el ser humano: la infertilidad. En el Perú, no existe regulación específica sobre estas técnicas, más allá de lo establecido en el artículo $7^{\circ}$ de la Ley General de Salud; siendo que el uso de las TERAS, incluido el llamado "vientre subrogado" son una realidad cada vez más frecuente en nuestro país. El presente artículo plantea algunas reflexiones sobre los nuevos retos que enfrenta el derecho ante las nuevas tecnologías, en materia de reproducción humana asistida; a partir de un proceso de amparo en el que se discute la filiación de dos menores (mellizos) procreados por medio de estas técnicas

* Historiadora-Abogada PUCP.

Magíster en Docencia Universitaria (UAB-Chile)

Docente de la Facultad de Derecho y Ciencia Política-URP

roxanarodriguezcadilla@gmail.com y con el apoyo de una gestante-colaboradora. Es decir, un caso de "vientre subrogado" en la modalidad de "vientre solidario", cuya sentencia firme reconoce la maternidad de quien no aportó el óvulo, ni llevó a cabo la gestación. Se trata de una resolución que declara como madre, para todos sus efectos legales y no legales, a quien tuvo exclusivamente la voluntad para procrear, planteando un nuevo supuesto de filiación, de tipo "afectivo-social", que genera jurisprudencia en esta materia.

\section{Palabras clave:}

"vientre de subrogado" "vientre solidario" "vientre de alquiler" - técnicas de reproducción humana asistida - filiación - derecho genético - derecho de familia - bioética - bioderecho biojurídica - biotecnología.

\section{Abstract}

The so-called Assisted Human Reproduction Techniques (TERAS) constitute a true technological revolution that is being applied to human life and procreation. The so-called "miracles" of modern science have made it possible to solve one of the problems of grea- 
test concern for the human being: infertility. In Peru, there is no specific regulation on these techniques, beyond what is established in Article 7 of the General Health Law; being that the use of TERAS, including the so-called "surrogate belly" are an increasingly frequent reality in our country. The present article raises some reflections on the new challenges that face the right before the new technologies, in the matter of assisted human reproduction; from an amparo process in which the filiation of two minors (twins) procreated through these techniques and with the support of a pregnant-collaborator is discussed. That is to say, a case of "surrogate belly" in the modality of "solidary belly", whose firm sentence recognizes the motherhood of those who did not bring the ovum, nor carried out the gestation. It is a resolution that declares as a mother, for all its legal and non-legal effects, who had exclusively the will to procreate, proposing a new assumption of affiliation, "affective-social" type, which generates jurisprudence in this matter.

\section{Keywords}

"Belly of surrogacy" - "belly of solidarity" "belly of rent" - techniques of assisted human reproduction - filiation - genetic law - family law - bioethics - bioterrorism - biojuridic - biotechnology

\section{Introducción}

Un evento determinante en el desarrollo de las TERAS, se llevó a cabo cuando los doctores Patrick Steptoe (ginecólogo) y Robert Edwards (fisiólogo) consiguieron que una pareja estéril tuviese descendencia. El logro se llevó a cabo mediante un procedimiento de fecundación in vitro y posterior transferencia embrionaria (FIVET). Edwards había logrado desarrollar una manera eficaz de fertilizar óvulos humanos fuera del vientre materno y Steptoe aportó el método para retirar los óvulos de los ovarios.
El embrión, así fertilizado, fue transferido con éxito al vientre de su madre quien, un 25 de julio de 1978, dio a luz a Louise Joy Brown, la primera "bebé probeta" en el mundo ${ }^{1}$.

En el año 2010, el británico Robert Edwards, de 85 años fue galardonado con el Premio Nobel de Medicina, por el desarrollo del tratamiento de la fecundación in vitro. Ello, por considerar que sus descubrimientos hicieron posible el tratamiento de la esterilidad que afecta a una gran proporción de la humanidad y a más de $10 \%$ de las parejas en el mundo ${ }^{2}$.

En el caso peruano, este mismo acontecimiento tuvo lugar en 1989 y estuvo a cargo de equipo conformado por los doctores Luis Noriega Hoces, Ladislao Prazac Krofta y el biólogo Guillermo Llerena Cano del Grupo PRANOR. Ello dio como resultado que, en 1990 naciera Victoria, el primer bebé peruano fecundado por medio de un procedimiento de FIVET $^{3}$.

Desde aquel acontecimiento revolucionario en Inglaterra, han pasado ya casi 40 años, y 27 desde su implementación en el Perú; años durante los cuales la FIVET ha logrado pasar de sus probabilidades de éxito inicial, que fueron de una en un millón, a lograr tasas de efectividad del $30 \%$ al $50 \%$ o más, dependiendo de las condiciones que intervienen en el procedimiento, siendo la edad de la madre un factor de especial relevancia ${ }^{4}$.

1 VARSI ROSPIGLIOSI, Enrique (1995). Derecho genético: principios generales. Lima, Editora Normas Legales, p. 194

2 El Nobel de Medicina fue para Robert Edwards, padre de fecundación in vitro. Cfr. http://www. docsalud.com/articulo/1264/el-nobel-de-medicina-fue-para-robert-edwards-padre-de-fecundaci\%C3\%B3n-in-vitro. (fecha de consulta 5 de septiembre de 2016)

3 LLERENA CANO, Guillermo (2014). Veinticinco años de Reproducción Humana Asistida en el Perú. En Vox Juris. Vol.28 No 2. P.151.

4 Entrevista al Doctor Marcelo Velit de la Clínica INMATER (23 de agosto de 2017) 
El perfeccionamiento y desarrollo de las TERAS ha conllevado que, para el año 2010, cuatro millones de personas en el mundo nacieran por medio de ellas y la cifra sigue en aumento, ya que hoy se habla de más de cinco millones de nuevos seres humanos resultantes de la aplicación de estas técnicas ${ }^{5}$.

En el caso Perú, aunque no existen cifras oficiales, se sabe que las clínicas de fertilidad que ofrecen sus servicios superan largamente la decena y son muchos más los consultorios particulares que también empiezan a abrir sus puertas al uso de estas técnicas.

Asimismo, para el año 2014, la Sociedad Peruana de fertilidad, calculaba en $4,500^{6}$, aproximadamente, los procedimientos de este tipo de llevan a cabo cada año, número que sigue en aumento como tendencia a nivel mundial 7 .

Este incremento en el uso de las TERAS se encuentra vinculado al hecho de que cada vez son más las parejas en el mundo que presentan problemas para concebir; lo cual se debe, entre muchos otros factores, a condicionamientos culturales propios del mundo actual, entre los que destaca la postergación o procastinación de la maternidad/paternidad.

5 CELIS LÓPEZ, Alfredo (2012). "Inseminación intrauterina en el momento actual" en Revista Peruana de Ginecología y Obstetricia. Vol.58, № 2, p.108. En el 2013, las cifras pasaron a ser 5 millones y esta tendencia continúa al alza

6 DIARIO EL COMERCIO. Peruanas ofrecen alquilar su vientre a S/.70 mil en internet. Domingo 22 De Junio del 2014. Cfr. http://elcomercio.pe/ sociedad/lima/peruanas-ofrecen-alquilar-su-vientre-s70-mil-internet-noticia-1737829. (fecha de consulta 4 de setiembre del 2016)

7 DIARIO REPÚBLICA. Récord de bebés nacidos por Fecundación In Vitro en Estados Unidos. http://pequelia.republica.com/preconcepcion/record-de-bebes-nacidos-por-fecundacion-in-vitro-en-estados-unidos.html
Las razones de esta procastinación pueden ser muchas: porque quieren ser padres a una edad con mayor madurez afectiva, porque están terminando una carrera, porque están en busca de un trabajo que les asegure una estabilidad económica, porque desean viajar y disfrutar de un tiempo propio o tal vez conseguir determinados bienes materiales, etc.

El hecho es que existe un reloj biológico que, en el caso de las mujeres, es mucho más corto ya que se estima que la edad reproductiva óptima es aproximadamente entre los 20 y 30 años; sin embargo, hoy por hoy, el avance biotecnológico que han experimentado las TERAS permite que ese reloj biológico se pueda extender muchos años más, incluso hasta edades que exceden el límite que marca la naturaleza, es decir, después de la menopausia (fenómeno de las llamadas madres-abuelas) ${ }^{8}$.

Es en este contexto que, como parte del desarrollo de las TERAS, encontramos la aparición de la técnica del útero subrogado, también llamado vientre sustituto. En este supuesto, el embrión fecundación in vitro, lo cual se puede llevar a cabo con material genético de la propia pareja (fecundación homóloga) o con donación de uno o ambos gametos (fecundación heteróloga); es transferido al vientre de una tercera persona (gestante-colaboradora) para que sea la encargada de gestar el embara-

8 RODRÍGUEZ-CADILLA PONCE, María del Rosario (2016) Implicancias bioéticas y biojurídicas de las Técnicas de Reproducción Asistida en el caso de la llamada maternidad tardía. Tesis para optar por el grado de Magíster. Universidad Católica Santo Toribio de Mogrovejo (USAT) Lima-Chiclayo. (Inédita) Si bien los rangos de edad varían entre los diversos autores, muchos de ellos consideran que la mejor edad para concebir es entre los 20 y 30 años. Tenemos por ejemplo el artículo: Barrios I. El Boom de las Madres Abuelas. Sin Mordaza. Argentina [Periódico en internet]. Abr 20 de 2015]. Disponible en: http:// www.sinmordaza.com/noticia/298855-el-boom-delas-madres-abuelas.html. (fecha de consulta 14 de julio de 2017) 
zo de la pareja que tiene la voluntad procreacional.

En aquellos casos en que media una compensación económica es que suele hablarse de "vientre de alquiler". Sin embargo, también existe la figura del "vientre solidario", como en el caso objeto del presente artículo, en el que la colaboración de una tercera persona en el proceso de gestación, se da por razones muy distintas a la de la compensación monetaria.

En todo caso, el procedimiento antes mencionado, ya no es ajeno a la realidad peruana. Muchas de las parejas que acuden a una clínica de fertilidad en nuestro país se encuentran en imposibilidad de gestar su propio embarazo por diversas razones de salud de la mujer; que van, desde antecedentes de abortos espontáneos, que le impiden mantener el embarazo una vez producida la implantación; o, incluso, por haber perdido el aparato reproductor femenino, como resultado de una histerectomía, por ejemplo.

A pesar de que ya son muchos los casos de este tipo que se presentan en nuestro país, muy pocos han llegado al Poder Judicial y, en todos los casos se tramitaron por la vía ordinaria ${ }^{9}$; por lo que el proceso de amparo que se presenta, y que cuenta ya con sentencia firme, es el primer caso litigado en vía constitucional en el Perú. Es así que, a partir de este caso concreto, plantearemos algunas reflexiones sobre los retos que impone al derecho el tema de la

9 Casos de impugnación de Maternidad: sentencia del 6 de enero del 2009, Juzgado decimoquinto especializado de familia, (Expediente $\mathrm{N}^{\circ}$ 183515-200600113); Casación No 5003-2007- Lima, Sala Civil Permanente de la Corte Suprema de Justicia de la República, sentencia del 8 de mayo del 2008; y, sobre nulidad de acto jurídico, sentencia del 11 de agosto de 2011, Sala Civil Permanente de la Corte Suprema de Justicia de la República; (Casación 4323-2010 Lima) subrogación de vientre como parte del proyecto de vida de la persona.

\section{Presentación del caso:}

En enero del 2005, se produce la unión matrimonial que da origen a la sociedad conyugal que llamaremos "AB". Luego de intentar tener hijos durante años, sin resultado positivo alguno, la pareja decidió recurrir a las técnicas de reproducción asistida para el tratamiento de su evidente infertilidad ${ }^{10}$.

Para el año 2010 se determinó que los óvulos de la señora "B" no alcanzaban el nivel de maduración necesario, por lo que resultaban inviables para la realización de la FIVET. Es así que se recurre a la técnica de la "ovodonación" y utilizando el aporte espermático del señor "A"; y un óvulo de donante anónima, se logra fecundar un embrión que fue transferido al útero de la señora "B". Sin embargo, el procedimiento no tuvo éxito y el embarazo devino en un aborto. Tras ello, los médicos concluyeron que la única alternativa que le quedaba al matrimonio era la modalidad de vientre subrogado.

En este sentido, la decisión de llevar a cabo el procedimiento recurriendo a la "ovodonación" y a la figura del útero subrogado", de manera conjunta, respondió a una evaluación médica exhaustiva en la que se determina

10 Organización Mundial de la Salud (OMS) define la infertilidad como como una enfermedad del sistema reproductivo definida como la incapacidad de lograr un embarazo clínico después de 12 meses o más de relaciones sexuales no protegidas. Glosario de terminología en Técnicas de Reproducción Asistida (TRA).

Versión revisada y preparada por el International Committee for Monitoring Assisted Reproductive Technology (ICMART) y la Organización Mundial de la Salud (OMS). Disponible en: http://www.who. int/reproductivehealth/publications/infertility/art terminology es.pdf?ua=1 (fecha de consulta 24 de agosto de 2017) 
que las condiciones de salud y capacidad reproductiva de la señora "A" hacían imposible lograr un embarazo con óvulos propios; así como, una gestación que llegase a término. Es ante esta situación que una amiga del matrimonio; la señora "C", con quien compartían no solo una amistad de muchos años, sino también la misma fe religiosa, se ofreció a llevar el embarazo.

La señora "C", casada y madre de 3 hijos, conversó con su esposo, el señor “D” y decidió prestar su ayuda para hacer posible la mater- nidad/paternidad de la sociedad conyugal infértil. Es así que ambas parejas suscribieron un acuerdo privado de útero subrogado (que no implicó contraprestación económica alguna) y que dio origen al embarazo por subrogación del que nacieron los mellizos "XY". Cabe recalcar que el embrión fue fecundado con los espermatozoides del señor A y un óvulo donado anónimamente, para luego ser trasferido al útero de la señora "C" quien solo gestó el embarazo, pero no aportó ninguna carga genética. El siguiente esquema puede aclarar el proceso que se viene comentando:

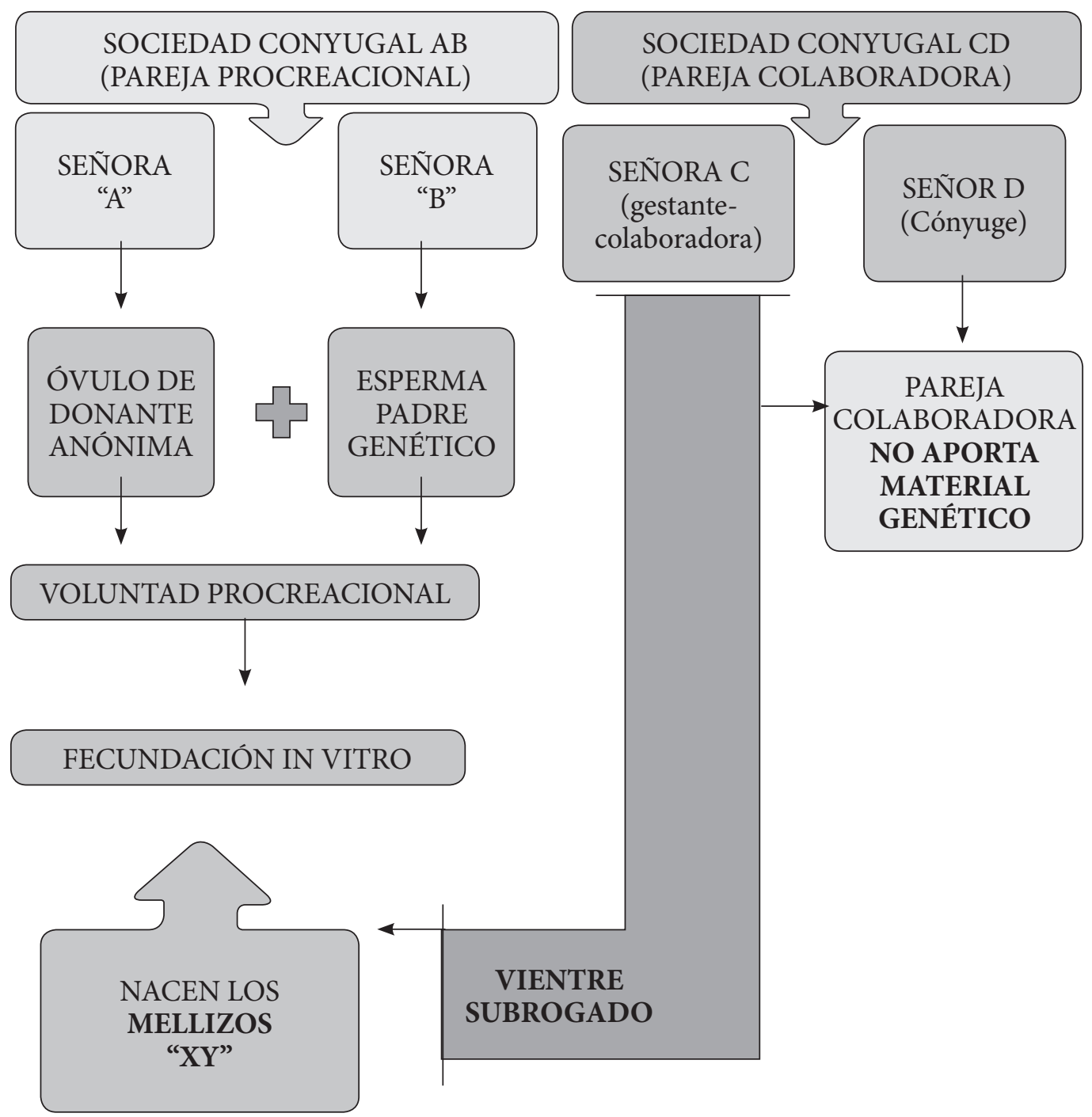


El 19 de noviembre del 2015, la señora "C" dio a luz a dos mellizos en el Instituto Nacional Materno Perinatal (ex Maternidad de Lima). En el Certificado de Nacido Vivo (CNV) de los menores se consignó como madre a la señora "C" y como padre declarado al señor "A", pese a que ella había dicho que el embarazo era producto de una TERA y que el óvulo fecundado tampoco era suyo. El Reniec emitió las actas registrales de los bebes con los datos señalados por el personal de la Maternidad.

Como se desprende de los hechos señalados la problemática jurídica presentada resultaba más que compleja:

- $\quad$ Respecto de la señora "A": Habiendo sido la mujer que tuvo la voluntad procreacional y quien con su pareja (el señor "B") acudió a la clínica CEFRA para llevar a cabo el procedimiento que le permitiera ser madre, quedaba fuera de la ecuación, al no serle reconocido ningún derecho sobre los menores. Asimismo, sería la cónyuge afectada por una supuesta “infidelidad" del señor "B" en tanto fue declarado padre de los menores.

- $\quad$ Respecto del señor "B": si bien fue declarado como padre por la gestante y consignado su apellido en las actas de nacimiento, se veía impedido de efectuar el reconocimiento de paternidad respectivo en tanto que con ello estaría convalidando una situación errónea. Es decir, sus hijos estarían siendo considerados hijos extramatrimoniales implicando ello una "infidelidad" con respecto a la señora "A".

- $\quad$ Respecto de la señora “ $C$ ": siendo casada y madre de tres hijos, además de no tener correspondencia genética alguna con los menores nacidos por útero subrogado estaría siendo considerada madre para todos sus efectos, lo que implicaría imponerle una maternidad a quien solo colaboró solidariamente con la gestación. Asimismo, se le consideraría infiel respecto del señor " $D$ ".

- $\quad$ Respecto del señor " $D$ ": pese a que no participa de ninguna forma en el proceso de concepción y posterior parto, podría ser considerado padre por la presunción "Pater is est"; o, en su defecto, sería el cónyuge afectado por la supuesta "infidelidad" de la señora "C".

Frente a la situación antes descrita, el derecho público no puede dejar de lado los derechos fundamentales y principios constitucionales que se ven afectados en el caso concreto, como es el caso del Principio de Interés Superior del Niño, su derecho a la identidad y los derechos de las parejas involucradas al libre desarrollo de su personalidad, a su plan de vida, a formar una familia; así como, sus derechos sexuales y reproductivos.

En conclusión, tenemos un matrimonio que ha hecho uso de medios legales para tener hijos y fundar una familia en un sentido pleno; pero que, sin embargo, lejos de ser protegida, estaba siendo perjudicada, junto con la pareja colaboradora; puesto que se reconoció como madre legal a quien no tenía correspondencia genética, sin tomar en consideración la naturaleza excepcional que da origen y existencia a los menores en cuestión.

\section{El Procedimiento ante el Registro Nacional de Identidad y Estado Civil-RENIEC}

Producido el nacimiento, y consignados erróneamente los apellidos de ambos menores sobre la base de los estipulado en el CNV, se so- 
licitó al RENIEC la rectificación de las respectivas actas de nacimiento emitidas, de manera que se consignara en las mismas el apellido de la mujer que tuvo la voluntad procreacional y no así de quién dio a luz a los menores.

Es importante señalar que en ningún caso se solicitó a RENIEC aplicar control difuso de las normas (como asumió el demandado), en la medida que sobre dicha situación ya se ha pronunciado el Tribunal Constitucional con relación al caso Consorcio Requena, donde prohíbe la aplicación de la figura del control difuso por parte de los órganos colegiados de la Administración Pública con alcance nacional. ${ }^{11}$

33. (...) permitir que los tribunales administrativos $u$ órganos colegiados realicen control difuso de constitucionalidad, afecta el sistema de control dual de jurisdicción constitucional establecido en la Constitución y reservado para el Poder Judicial y/o el Tribunal Constitucional, según corresponda, conforme a los artículos $138^{\circ}$ y $201^{\circ}$ de la Constitución, respectivamente.

En ese sentido, incluso afecta al principio de división de poderes, dado que se permite que un tribunal administrativo, que forma parte del Poder Ejecutivo, controle las normas dictadas por el Poder Legislativo, lo que, conforme a

11 El caso Consorcio Requena del 18 de marzo de 2014 (STC 04293-2012-PA/TC) disponible en: http://www. tc.gob.pe/jurisprudencia/2014/04293-2012-AA.pdf; modifica el precedente vinculante establecido en la Sentencia del Tribunal Constitucional en el caso Salazar Yarlenque, que admitía el control difuso en sede administrativa, en casos de evidente o manifiesta vulneración de derechos fundamentales. Cabe mencionar que el ejercicio de esta potestad en EE.UU fue conferido por la Corte Suprema en el caso Marbury vs Madison en 1803.

\begin{abstract}
la Constitución, solo puede ocurrir en un proceso jurisdiccional y no en uno de naturaleza administrativa. ${ }^{12}$
\end{abstract}

En este sentido, lo solicitado al RENIEC fue el reconocimiento del carácter normativo de la constitución; y, por lo tanto, la obligación de todas las instancias del Estado, incluso las administrativas, y hasta entre particulares, de poder aplicar directamente los derechos constitucionalmente protegidos.

Por otra parte, y existiendo afectación a los derechos fundamentales de los menores y de las parejas involucradas, como se ratificó en el proceso de amparo; se solicitó que las normas bajo las cuáles opera la RENIEC fueran interpretadas a la luz de nuestra Constitución, de los derechos que ella nos reconoce y que el Tribunal Constitucional ha definido en su contenido esencial; así como, de las normas imperativas del derecho internacional de los derechos humanos que fuesen aplicables al caso concreto. La negativa de RENIEC a la rectificación solicitada constituyó el acto lesivo necesario para dar inicio al proceso de amparo.

Ese sentido, la argumentación planteada por la entidad demandada desconoció en forma sistemática la obligación del Estado en velar por el interés superior del niño, y en particular, su derecho a la identidad y al desarrollo normal de su personalidad, el cual se encontrará realmente tutelado, siempre que proceda la inscripción de la pareja beneficiaria (pareja "AB") como padres de los menores

Respecto de lo antes mencionado, la sentencia de segunda instancia señala que los efectos que contiene tanto la sentencia de vista como los de la de primera instancia, no se ha declarado el control difuso de las normas que

12 Caso Consorcio Requena del 18 de marzo de 2014 (STC 04293-2012-PA/TC) disponible en: http://www. tc.gob.pe/jurisprudencia/2014/04293-2012-AA.pdf 
se invocan, lo que en efecto tampoco correspondía a la entidad demandada, ni fue solicitado por los demandantes. Sin embargo, a ella sí le correspondía su interpretación conforme a la Constitución, lo que no fue ejercido por la entidad demandada y que configura la vulneración de los derechos constitucionales invocados en la demanda.

\section{El Proceso de Amparo}

En primera instancia, la sentencia del 21 de febrero de 2017, emitida por el Quinto Juzgado Especializado en lo Constitucional, recogió los argumentos planteados por ambas parejas demandantes, en nombre propio y en representación de los menores involucrados, realizando el siguiente análisis constitucional:

- Que las resoluciones impugnadas emitidas por RENIEC, al no considerar a la señora "A" como la madre de los menores, no sólo se estaría vulnerando su derecho a la salud reproductiva, sino también, los derechos de las parejas demandantes a la intimidad o vida privada y al libre desarrollo de su personalidad, en tanto a su proyecto de vida se refiere. Asimismo reconoce la afectación del derecho a la identidad de los menores y la tutela de su interés superior.

- $\quad$ Al respecto, la normativa y la jurisprudencia convencional que vincula al Estado, han dispuesto en relación a este escenario, que el derecho a la vida se relaciona con la autonomía reproductiva y el acceso a servicios de salud reproductiva, lo cual involucra el derecho de acceder a la tecnología médica necesaria para ejercer ese derecho. Es decir, que el derecho a la salud reproductiva reconoce la potestad de las mujeres a que de ma- nera informada, puedan recurrir no sólo a técnicas científicas de reproducción disponibles, sino también al apoyo de terceras personas (casos de maternidad subrogada) para poder alcanzar la condición de madre.

- Que al no existir normativa interna que prohíba el uso de estas técnicas médicas para la concepción, no existirían razones para que el Estado rechace la validez o resultados de estos métodos de reproducción. Es decir, considera que "todo lo que no está prohibido está permitido" justificando la legalidad de los hechos presentados con la demanda.

- Asimismo, al amparo de lo reconocido por el ordenamiento convencional, el Juzgado realiza una interpretación extensiva del artículo $7^{\circ}$ de la Ley General de Salud, cuyo texto original limita el ejercicio del derecho de acudir a técnicas de reproducción asistida a casos en los cuales el elemento genético de la madre coincida con su condición de gestante; sobre el cual se concluye que las demás situaciones no previstas por este artículo no necesariamente deban encontrarse proscritas, de ser ese el caso, ello devendría en inconstitucional o contrario a la presunción de libertad; es decir, se presumiría limitaciones al derecho a la salud reproductiva.

- Teniendo claro que el uso de las TERAS no constituye un mecanismo prohibido por la ley, este Juzgado resuelve que su uso sólo es posible cuando tuvieran como destino a la formación de la familia- como lo es en el presente caso- , contribuyendo de esta manera al ejercicio de este derecho previsto tanto a nivel consti- 
tucional como en los diversos Pactos Internacionales suscritos por el Perú.

- Ahora bien, al encontrarse los demandantes en todo su derecho a fundar una familia, acudiendo a los métodos científicos y legales que permite el ordenamiento jurídico peruano; y al no haber dudas sobre la posición que ellos ocupan frente a los menores, RENIEC no puede cuestionar ni obstruir la manera en cómo se constituye esta familia, por el contrario, este debe brindar las facilidades para que sea instituida como tal y evitar que la situación familiar se vea alterada.

- $\quad$ Por lo tanto, al reconocer este Juzgado el derecho a la salud reproductiva, el libre desarrollo de la personalidad y al de fundar una familia a los demandantes; tiene a bien declarar FUNDADA la demanda de amparo y NULAS las Resoluciones Registrales $\mathrm{N}^{\circ}$ 299-2016-ORS B O R J - J R 10 L I M - G O R / RENIEC y 300-2016-ORSBORJ-JR10LIM-GOR/RENIEC, disponiendo se anulen las actas de nacimiento 30022117908 y 3002217885 . Asimismo, se ordena en el plazo de 02 días que RENIEC emita nuevas partidas de partidas de los menores, donde conste como sus apellidos los de la pareja que tuvo la voluntad procreacional (pareja $\mathrm{AB}$ ), permitiéndoles también suscribir las nuevas actas de nacimiento.

En segunda instancia, la Tercera Sala Civil de la Corte Superior de Justicia de Lima, en sentencia emitida el 28 de junio de 2017; ratifica la apelada, recogiendo los argumentos antes expresados con fundamento en una amplia recopilación de normas y jurisprudencia tan- to nacional como internacional ${ }^{13}$ y señalando, además, lo siguiente:

- $\quad$ Sobre el parentesco que es reconocido por la sentencia respecto a ambos padres (pareja "AB") con los menores tutelados, debe precisarse que no puede ser sanguíneo, pues de serlo, sólo tutelaría el derecho del señor $B$ (padre genético) mas no el de su cónyuge, la señora " $\mathrm{B}$ " ni puede ser adoptivo, pues el señor " $B$ " no puede ser padre adoptivo de sus propios hijos biológicos; por lo que nuevamente nos encontramos frente a un supuesto excepcional no regulado por la ley nacional, producto de la utilización de las Técnicas de Reproducción Asistida, en cuyo caso deberá reconocerse al señor "A" y a la señora "B" un parentesco afectivosocial producto de la inicial voluntad procreacional que siempre tuvieron ambos padres.

- Finalmente, respecto a la supuesta aplicación del control difuso de la constitucionalidad de las leyes, corresponde precisar que en el análisis tanto de la Sentencia de primera instancia como en el de la presente Sentencia de Vista, no se ha declarado la inaplicabilidad de los artículos respectivos de la determinación de los vínculos filiales dentro del matrimonio, ni mucho menos el artículo $7^{\circ}$ de la Ley General de Salud por presunta incompatibilidad con la Constitución, sino que se les ha dado una

13 Corte Interamericana de Derechos Humanos respecto al Caso Artavia Murillo y otros ("Fecundación in vitro”) vs. Costa Rica, donde dicho Colegiado halló responsabilidad en dicha nación por la vulneración de los artículos 5.1, 7, 11.2 y 17.2, en relación con el artículo 1.1 de la Convención Americana sobre Derechos Humanos. 
interpretación conforme a la Constitución, en tanto existe un vacío normativo respecto al caso concreto, pues no resultan normas de carácter prohibitivo sobre la situación planteada en el presente proceso, sino únicamente que no regulan de forma expresa los supuestos que de forma particular han sido presentados en autos.

\section{Reflexiones finales: ¿Mater Semper certa est?}

Desde el mundo romano ha regido un principio en derecho de familia, aquel que dice que la madre siempre es cierta o como reza en la cultura popular: "Hijos de mi hija tendré, de mi hijo no lo sé”. Sin embargo, más allá de la controversia que, sin duda, genera el uso de la técnica de vientre subrogado; lo cierto es que el Principio de Mater Semper Certa Est, que hasta ahora había sido una máxima absoluta de nuestra legislación en materia de familia ya admite prueba en contrario.

$\mathrm{Al}$ respecto, cabe decir que en el Perú no existe una regulación específica en materia de reproducción asistida. La única norma con la que contamos, como se señalaba en las sentencias resumidas, es el artículo 7 de la Ley General de Salud artículo, cuyo texto dice lo siguiente:

Artículo 7.- Toda persona tiene derecho a recurrir al tratamiento de su infertilidad, así como a procrear mediante el uso de técnicas de reproducción asistida, siempre que la condición de madre genética y de madre gestante recaiga sobre la misma persona. Para la aplicación de técnicas de reproducción asistida, se requiere del consentimiento previo y por escrito de los padres biológicos.
Está prohibida la fecundación de óvulos humanos con fines distintos a la procreación, así como la clonación de seres humanos (Subrayado nuestro). ${ }^{14}$

Más allá de cuál fue la intención del legislador al redactar esta norma, lo cierto es que la Ley tiene vida propia y adquiere el sentido que le da el intérprete el mismo que en nuestro ordenamiento jurídico debe ser acorde con nuestra Constitución y los tratados internacionales de los cuáles el Perú forma parte. En todo caso, la terrible técnica legislativa de la que adolece esta norma hace que la interpretación, acto que se encuentra siempre presente en cualquier operador del derecho, tenga que ser mucho más amplia en este caso concreto. ${ }^{15}$

Es importante destacar que, tal como se confirma en ambas sentencias, la norma no contiene una prohibición ni del útero subrogado ni de la ovodonación, pues si el legislador hubiera querido prohibir la ovodonación o la subrogación lo hubiese establecido con la misma claridad con la que prohíbe la clonación o el uso de las TERAS con fines distintos a la procreación. Lo que sí resulta innegable es que la norma reconoce el derecho de toda persona a tratar su infertilidad y a hacer uso de las TERAS con dicho fin. Lo que requiere de una interpretación más exhaustiva es la afirmación del legislador de que la condición de madre genética y madre gestante, según reza la norma, deba recaer sobre la misma persona.

14 Ministerio de Salud. Ley No 26842. Ley General de Salud. Disponible en: http://www.minsa.gob.pe/ renhice/documentos/normativa/Ley\%20268421997\%20-\%20Ley\%20General\%20de\%20Salud\%20 Concordada.pdf. (fecha de consulta 23 de agosto)

15 GUASTINI, Riccardo: "Estudios sobre la Interpretación Jurídica”. Editorial Porrúa. Universidad Nacional Autónoma de México. Quinta edición, 2003. México. Págs. 3 y 5 
Siguiendo a Paula Siverino, ${ }^{16}$ el sentido literal de este condicionamiento cae en el absurdo, puesto que si la madre genética y gestante es la misma persona; estamos hablando, en la gran mayoría de los casos, del supuesto natural de embarazo que no requiere, por lo tanto, del uso de las técnicas de reproducción asistida. Por otra parte, hay supuestos de maternidad subrogada en donde la gestante aporta también el material genético, lo cual es muy cuestionable incluso en los países donde la subrogación está ampliamente permitida; y que, sin embargo; según la interpretación literal de esta norma sería válido.

Como señala esta autora, las prohibiciones no pueden interpretarse de manera analógica, sino que deben estar explicitadas o se vulneraria el principio que establece que 'aquello no está prohibido, está permitido'. Por otra parte, admitir la fecundación heteróloga con material genético masculino, pero asumir que se impide lo mismo cuando el material genético es femenino originaría una discriminación por razón de género ${ }^{17}$.

16 SIVERINO, Paula (2012). Una mirada desde la bioética jurídica a las cuestiones legales sobre la infertilidad en el Perú. Revista Peruana de ginecología y obstetricia. No 58: pp. 213-219. Cfr. http://sisbib.unmsm.edu.pe/bvrevistas/ginecologia/vol58 n3/pdf/ a09v58n3.pdf

17 SIVERINO, Paula. (2010) ¿Quién llamó a la cigüeña? Maternidad impugnada e identidad genética, reflexiones a propósito de dos sentencias peruanas. Revista Jurídica UCES. Disponible en: http:// dspace.uces.edu.ar:8180/xmlui/bitstream/handle/123456789/906/Quien llamo cig Silverino.pdf?sequence $=1$ (fecha de consulta 12 de julio de 2017)
Dicho esto, no es posible asumir la existencia de una prohibición del útero subrogado; por lo que ello estaría dentro de la esfera de libertad y autonomía de la persona, además de que están de por medio los derechos sexuales y reproductivos de los padres, así como el derecho a la identidad de los menores, entre otros.

No siendo contrario a la ley, y menos aún a nuestra Constitución que junto con los tratados internacionales reconoce los derechos humanos que se estarían vulnerando con una interpretación distinta a la planteada, queda pendiente el tema de la "moral" y las "buenas costumbres". En nuestra opinión, se trata de expresiones ambiguas que deberían, en el mejor de los casos, desaparecer de nuestro ordenamiento jurídico; pero, mientras existan, solo pueden (y deben) ser entendidas como una garantía para los derechos fundamentales de las personas y, en ningún caso, como una defensa particular de una moral religiosa determinada, por más mayoritaria que esta pueda ser.

Como venimos señalando, no existe prohibición legal a la figura del útero subrogado, ni vulneración a la "moral" o las "buenas costumbres"; en tanto que lo "moral" es el propio orden constitucional y los derechos que él garantiza; y, las "buenas costumbres" solo pueden ser aquellas que sean acordes con esta misma finalidad.

En un mundo en que la tecnología ha avanzado vertiginosamente y el derecho aún no logra ponerse al día, es determinante la interpretación de la ley con base en los derechos constitucionales que ella debe promover. El vacío normativo que se presenta en el caso narrado pone en evidencia la urgente necesidad de volvernos a aproximar al concepto de derecho en su relación intrínseca y dinámica, con la sociedad que pretende regular. 


\section{REFERENCIAS BIBLIOGRÁFICAS:}

\section{BARRIOS, I.}

El Boom de las Madres Abuelas. Sin Mordaza. Argentina. Lunes 20 de abril de 2015. (Fecha de consulta 14 de julio de 2017) Disponible en: http://www.sinmordaza.com/noticia/298855-el-boom-de-las-madres-abuelas.html.

\section{CELIS LÓPEZ, A.}

(2012). "Inseminación intrauterina en el momento actual" en Revista Peruana de Ginecología y Obstetricia. Vol.58 (2).

\section{GUASTINI, R.}

"Estudios sobre la Interpretación Jurídica”. Editorial Porrúa. Universidad Nacional Autónoma de México. Quinta edición, 2003. México

\section{LLERENA CANO, G.}

(2014). Veinticinco años de Reproducción Humana Asistida en el Perú. En Vox Juris. Vol.28 (2).

\section{MINISTERIO DE SALUD (MINSA).}

Ley No 26842. Ley General de Salud. (Fecha de consulta 23 de agosto). Disponible en: http://www.minsa. gob.pe/renhice/documentos/normativa/Ley\%2026842-1997\%20 -\%20Ley\%20General\%20de\%20 Salud\%20Concordada.pdf.

ORGANIZACIÓN MUNDIAL DE LA SALUD (OMS) \& INTERNATIONAL COMMITTEE FOR MONITORING ASSISTED REPRODUCTIVE TECHNOLOGY (ICMART).
Glosario de terminología en Técnicas de Reproducción Asistida (TRA). (Fecha de consulta 24 de agosto de 2017). Disponible en: http://www.who.int/reproductivehealth/publications/infertility/art terminology es.pdf?ua $=1$

\section{RODRÍGUEZ-CADILLA PONCE, M.}

(2016) Implicancias bioéticas y biojurídicas de las Técnicas de Reproducción Asistida en el caso de la llamada maternidad tardía. Tesis para optar por el grado de Magíster. Universidad Católica Santo Toribio de Mogrovejo (USAT) Lima-Chiclayo. (Inédita)

\section{SIVERINO, P.}

(2012). Una mirada desde la bioética jurídica a las cuestiones legales sobre la infertilidad en el Perú. Revista Peruana de ginecología y obstetricia. No 58. (Fecha de consulta 12 de julio de 2017). Disponible en: http://sisbib.unmsm.edu.pe/bvrevistas/ginecologia/vol58 n3/pdf/ a09v58n3.pdf

\section{SIVERINO, PAULA.}

(2010) ¿Quién llamó a la cigüeña? Maternidad impugnada e identidad genética, reflexiones a propósito de dos sentencias peruanas. Revista Jurídica UCES. (Fecha de consulta 12 de julio de 2017) Disponible en: http:// dspace.uces.edu.ar:8180/xmlui/ bitstream/handle/123456789/906/ Quien llamo cig Silverino.pdf?sequence $=1$ 


\section{VARSI ROSPIGLIOSI, ENRIQUE}

(1995). Derecho genético: principios generales. Lima, Editora Normas Legales.

\section{PERIÓDICOS DE INTERNET (LINKS)}

\section{DIARIO EL COMERCIO.}

Peruanas ofrecen alquilar su vientre a S/.70 mil en internet. Domingo 22 de junio del 2014. Disponible en: http://elcomercio.pe/sociedad/ $\underline{\text { lima/peruanas-ofrecen-alqui- }}$ lar-su-vientre-s70-mil-internet-noticia-1737829 (fecha de consulta 4 de setiembre del 2017)

DIARIO REPÚBLICA.

Récord de bebés nacidos por Fecundación In Vitro en Estados Uni- dos. Martes 18 de febrero de 2014 http://pequelia.republica.com/preconcepcion/record-de-bebes-nacidos-por-fecundacion-in-vitro-en-estados-unidos.html (fecha de consulta 10 de junio de 2017)

DOC.SALUD.

El Nobel de Medicina fue para Robert Edwards, padre de fecundación in vitro. Lunes 4 de octubre de 2010. Cfr. http://www.docsalud.com/ articulo/1264/el-nobel-de-medicina-fue-para-robert-edwards-padre-de-fecundaci\%C3\%B3n-in-vitro (fecha de consulta 5 de septiembre de 2017). 
